\title{
Association between Age and Histopathological Grade of Bladder Urothelial Carcinoma
}

\author{
Dionisius Alby, ${ }^{1}$ Abdul Hadi Hassan, ${ }^{2}$ Jupiter Sibarani ${ }^{3}$ \\ ${ }^{1}$ Faculty of Medicine Universitas Padjadjaran, ${ }^{2}$ Department of Anatomical Pathology Faculty of \\ Medicine Universitas Padjadjaran/Dr. Hasan Sadikin General Hospital Bandung, ${ }^{3}$ Department \\ of Surgery Faculty of Medicine Universitas Padjadjaran/Dr. Hasan Sadikin General Hospital \\ Bandung
}

\begin{abstract}
Background: Bladder cancer, particularly urothelial carcinoma, is prevalent in male and $\geq 55$ years old population. Grade of the bladder tumor affects clinical characteristics, management, and prognosis of the patient. This study aimed to analyze the association between age and histopathological grade of bladder urothelial carcinoma.

Methods: This cross-sectional analytical study was approved by the Ethical Clearance Committee of Dr. Hasan Sadikin General Hospital, involving 241 medical records of bladder urothelial carcinoma patients in the Department of Anatomical Pathology at Dr. Hasan Sadikin General Hospital during 2009-2013. Chisquare test was applied to 45 patients with complete record of histopathological grade.

Results: Most of the subjects were 65 years old. Male patients were the most frequent. The proportion of low-grade carcinoma in $<65$ years old age group was only $39.1 \%$, while in $\geq 65$ years old age group was $72.7 \%$. The proportion of high-grade carcinoma in $<65$ years old age group reached $60.9 \%$, which was $27.3 \%$ higher than in $\geq 65$ years old age group. Chi-square test result showed a statistically significant difference between histopathological grade of urothelial carcinoma in $<65$ years and $\geq 65$ years age groups $(p=0.023$ ).

Conclusions: Proportion of high-grade and low-grade urothelial carcinoma between $<65$ years and $\geq 65$ years age groups are statistically different; therefore, an association between age and histopathological grade of bladder urothelial carcinoma is shown.
\end{abstract}

Keywords: Age, bladder cancer, histopathological grade, urothelial carcinoma

\section{Introduction}

Bladder cancer ranks $11^{\text {th }}$ and contributes $3.1 \%$ of all the cancer incidence worldwide. Bladder cancer ranks $7^{\text {th }}$ in male with 330.000 incidences and mortality rate around 120.000 annually. ${ }^{1}$ The incidence is higher in male compared to female with 3-3.5: 1 ratio. $^{2}$ More than $90 \%$ bladder cancer are found in $\geq 55$ years old age group. ${ }^{3}$

Most malignant tumors originate from transitional cell, which then are classified as urothelial (transitional) cell carcinomas.2The grade of bladder tumor affects the patient's clinical feature, management, and prognosis. ${ }^{2,4-6}$

Unfortunately, in Indonesia, the populationbased data regarding cancer prevalence, incidence, and mortality rate have not been established yet. The existing data are hospitalbased data or the incidence rate estimated from neighboring countries. ${ }^{7}$

The increasing number of tobacco smokers, higher intensity of occupational chemical exposure, and aging population significantly increase the number of bladder carcinoma cases in developing countries. ${ }^{4}$ Many epidemiological studies reported this higher incidence of bladder urothelial carcinoma in the elderly group. ${ }^{2}$ However, there have been few studies that show the association between age and histopathological grade of bladder urothelial carcinoma. ${ }^{8}$ Therefore, this study aimed to analyze the association between age and histopathological grade of bladder urothelial carcinoma. 


\section{Methods}

The study subjects were patients with bladder urothelial carcinoma in the Department of Anatomical Pathology at Dr. Hasan Sadikin General Hospital during 2009-2013. The inclusion criteria for this research were bladder urothelial carcinoma cases with complete records of the patient's age and urothelial carcinoma histopathological grade. The exclusion criteria were cases that were histopathologically diagnosed as bladder urothelial carcinoma with incomplete data of the urothelial carcinoma grade. Observation was conducted with total sampling techniques of medical records data from 2009 to 2013.

This study was an analitical study with a cross-sectional design. Furthermore, this study compared the histopathological grade of bladder urothelial carcinoma between the elderly group and other age group to assess the association between age and histopathological grade of bladder urothelial carcinoma.

Generally, the worldwide cut off point for elderly group varies between 60-65 years old. This study took into consideration that in the bladder carcinoma management being 65 years old and over is a factor for not applying radical cystectomy, and also the increasing life expectancy in Indonesia, from 64.5 years old in 2000 to 69.65 years old in 2011. Therefore in this study, 65 years old and over were used as the cut off point for the elderly group.

This study was conducted by collecting secondary data from patient's medical records after obtaining permission from the Ethical
Clearance Committee of Dr. Hasan Sadikin General Hospital. Out of all the medical record data, only those that met the inclusion criteria were used in this study. Then, data from medical records were classified into several age groups. Subsequently, urothelial carcinoma histopathological grade of each group was observed.

The collected data were then analyzed with a statistical program. Moreover, the hypothesis testing for comparative study with categorical variable, Chi-square test, was used. The P-value of less than 0.05 was considered statistically significant.

\section{Results}

This dstudy used 245 primary bladder urothelial carcinoma cases recorded in the Department of Anatomical Pathology at Dr. Hasan Sadikin General Hospital during 2009-2013. The 241 cases with complete data regarding age on medical records showed that the mean age of the patients was $60.2 \pm 12.5$ years old with a median of 61 years old. The youngest case of bladder urothelial carcinoma was found in a-29-year-old patient, while the oldest was 87 years old. The male to female ratio reached 7.9:1, with the number of male patient was 214 cases (88.8\%). Out of the whole 241 cases, 45 cases were histopathologically graded, and included in the comparative hypothesis testing.

Furthermore, most subjects of this study were 65 years old. Additionally, the histogram figure also showed that the data were not

\section{Bladder Urothelial Carcinoma}

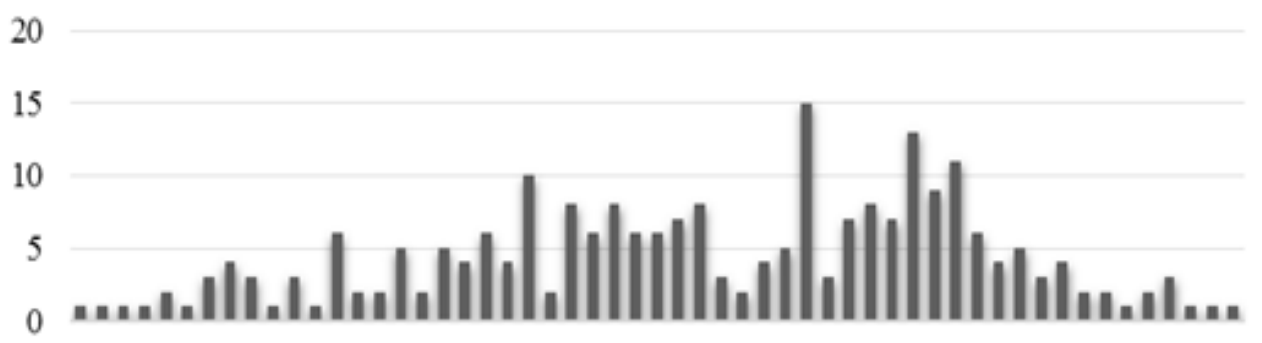

29313336384143454749515355575961636567697173757779828587 Age (y.o.)

Erequencies of bladder urothelial carcinoma

Figure Age Distribution of Bladder Urothelial Carcinoma 
Table Descriptive Statistic of Urothelial Carcinoma

\begin{tabular}{lcc}
\hline \multirow{2}{*}{ Urothelial carcinoma grade } & \multicolumn{2}{c}{ Age (y.o) } \\
\cline { 2 - 3 } & Mean \pm Std. Deviation & Minimum-Maximum \\
\hline Low-grade & $64.48 \pm 11.2$ & $35-83$ \\
High-grade & $57.95 \pm 13.7$ & $33-86$ \\
\hline
\end{tabular}

normally distributed (Figure).

According to the descriptive analysis, the mean age of high-grade urothelial carcinoma cases was $57.95 \pm 13.7$ years and low-grade urothelial carcinoma cases was $64.5 \pm 11.2$ years. According to the Saphiro-Wilk test, the normality testing for data distribution isused for age to histopathological grade variable, and showed that the data were normally distributed ( $p=0.065$ and $p=0.999$, consecutively lowgrade and high-grade) (Table).

Moreover, 20 cases of high-grade urothelial carcinoma were found with 14 cases from $<65$ years age group and 6 cases from $\geq 65$ years age group. Whereas, 25 cases of low-grade urothelial carcinoma were found with 9 cases from $<65$ years age group and 16 cases from $\geq 65$ years age group.

A cross tabulation was performed with the age group as independent variable and urothelial carcinoma grade classification as dependent variable. All cells in $2 \times 2$ table fulfilled the condition of expected value $>5$; thus, the Chi-square test could be conducted. The Chi-square test resulted in statistically significant difference between the proportion of urothelial carcinoma for both histopathological grade in $<65$ years age group and $\geq 65$ years age group. $(p=0.023)$.

\section{Discussion}

Bladder cancers are malignancies that occur in the wall structure of the bladder. Around 95\% bladder tumors originate from epithelial cells, hence its malignant form acquired the carcinoma suffix. ${ }^{2}$ Most malignant tumors originate from transitional cells, which are then classified as urothelial (transitional) cell carcinomas. ${ }^{2}$

The mean age of the bladder urothelial carcinoma patients in this study was 60.2 years. This result did not differ much from the previous result at Cipto Mangunkusumo General Hospital, Jakarta (56.5 years old) and several foreign studies (60.2-61.9 years old) ${ }^{6,8-10}$

The number of male bladder urothelial carcinoma cases greatly exceeded female cases. Male to female ratio reached 7.9:1. This result was still in the variation range reported in other researches $(6-10: 1){ }^{6,8-10}$ This result occurred because this study only analyzed the bladder urothelial carcinoma, while the proportion of urothelial carcinoma in female was not as high as male. ${ }^{11}$

The current use the grading system, was due to the result of the International Society of Urological Pathology (ISUP) consensus in 1998 which was adopted by the World Health Organization (WHO) in 2004. This system classifies bladder urothelial carcinoma into low and high grade. ${ }^{2}$ According to several studies, both bladder urothelial carcinoma grades differ in its molecular pathogenesis.

Deletions of $9 p / 9 q$ are found in more than $50 \%$ urothelial carcinoma of all types and grades. The deletions are also the early development of tumor cells., ${ }^{2,12,13}$ Alteration in fibroblast growth factor receptor 3 gene (FGFR3) and transforming protein p21 (HRAS) form non-invasive papillary urothelial carcinoma, low-grade. ${ }^{5,13}$ Whereas mutated p53 gene produces carcinoma in situ, noninvasive papillary urothelial carcinoma, highgrade and progression to infiltrating urothelial carcinoma. ${ }^{5,13}$ Besides, the bladder urothelial carcinoma spreading characteristic shows a tendency to specific grades; non-invasive to low-grade,while infiltrating to high-grade. ${ }^{13}$

In this study, there were differences in the proportion of low-grade and high-grade bladder urothelial carcinoma between $<65$ years age group and $\geq 65$ years age group. The proportion of low-grade carcinoma in $<65$ years age group was only $39.1 \%$, while in $\geq 65$ years age group was $72.7 \%$. The proportion of high-grade carcinoma in $<65$ years age group reached $60.9 \%, 27.3 \%$ than in $\geq 65$ years age group. The Chi-square analytical test resulted in statistically significant difference $(\mathrm{p}=0.023)$. This result suggested that there was an association between age and histopathological grade of bladder urothelial carcinoma.

Albeit, this result contradicted with several previous studies which showed increasing age associates with increasing proportion of poorly differentiated (low-grade) bladder 
urothelial carcinoma. ${ }^{8}$ This might be caused by several factors, such as insufficient data which met the inclusion criteria and classification of research subjects into two uneven age groups.

Limitations of this retrospective study were the difficulties of comprehensive data acquirements regarding bladder urothelial carcinoma patient's histopathologic grade. Besides, this study was a hospital-based study, so the available data did not cover the whole bladder urothelial carcinoma cases in the population. Therefore, a reconsideration of those factors may be required before the study results are utilized.

Further researches are expected to overcome the limitations in this study to prove the existence of an association between age and histopathological grade of bladder urothelial carcinoma. This can be carried out when the complete data regarding the histopathologic grade of bladder urothelial carcinoma in each patient's medical record are available as well as sufficient resources to conduct a community-based research. In addition, balancing the classification into different age groups can help to obtain better results.

The increasing proportion of elderly in the population lead to the increasing number of bladder cancer cases. Histopathological grade and age of bladder cancer patients are closely related to the patient's management and prognosis. ${ }^{2,4-6,14}$ Therefore, a good understanding between the two are required.

It can be concluded that bladder urothelial carcinoma is mostly found in male and 65 years old patients. Analytically, the proportion of low-grade and high-grade urothelial carcinoma differs between $<65$ years age group and $\geq 65$ years age group. thus, showing an association between age and histopathological grade of bladder urothelial carcinoma.

\section{References}

1. Ferlay J, Soerjomataram I, Ervik M, Dikshit $\mathrm{R}$, Eser S, Mathers C, et al. GLOBOCAN 2012 v1.0, cancer incidence and mortality worldwide: IARC cancer baseno. 11 [Internet] Lyon, France: IARC; 2013 [cited 2014 February 24]. Available from: http:// globocan.iarc.fr.

2. Epstein JI. The lower urinary tract and male genitalia system. In: Kumar V, Abbas AK, Fausto N, Aster JC, editors. 2010 robbins and cotran pathologic basis of disease. 8thed. Philadelphia: Saunders Elsevier; 2010. p. 976-981.

3. Ploeg M, Aben KH, Kiemeney L. The present and future burden of urinary bladder cancer in the world. World J Urol. 2009;27(3):289-293.

4. Belldegrun A, Rochelle JL, Shuch B. Urology. In: Brunicardi FC, Andersen DK, Billiar TR, Dunn DL, Hunter JG, Matthews JB, et al., editors. 2010 Schwartz's principles of surgery. 9thed. USA: The McGraw-Hill Companies, Inc; 2010.

5. Jacobs BL, Lee CT, Montie JE. Bladder cancer in 2010: how far have we come. Ca Cancer J Clin. 2010;60(4):244-272.

6. Wempy S, Chaidir AM, Marto S, Rainy U. Survival of patients with transitional cell carcinoma of the urinary bladder in Indonesia: a single institution review. Asian Pac J Cancer Prev. 2011;12:549-553.

7. Shin HR, Carlos MC, Varghese C. Cancer control in the Asia Pacific region: current status and concerns. Jpn J Clin Oncol. 2012;42(10):867-881.

8. Gupta P, Jain M, Kapoor R, Muruganandham $\mathrm{K}$, Srivastava A, Mandhani A. Impact of age and gender on the clinicopathological characteristics of bladder cancer. Indian J Urol. 2009;25(2):207-210.

9. Matalka I, Bani-Hani K, Shotar A, Bani Hani O, Bani-Hani I. Transitional cell carcinoma of the urinary bladder: a clinicopathological study. Singapore Med J. 2008;49(10):790-794.

10. Yavari P, Sadrolhefazi B, Mohagheghi MA, Mehrazin R. A descriptive retrospective study of bladder cancer at a hospital in Iran (1973-2003). Asian Pac J Cancer Prev. 2009;10(4):681-684.

11. IARC. World Cancer Report 2008. Lyon, France: IARC Library Cataloguing Data; 2008.

12. Kaufman DS, Shipley WU, Feldman AS. Bladder cancer. The Lancet. 2009;374(9685):239-249.

13. Pasin E, Josephson DY, Mitra AP, Cote RJ, Stein JP. Superficial bladder cancer: an update on etiology, molecular development, classification, and natural history. Rev Urol. 2008;10(1):31-43.

14. Shariat SF, Sfakianos JP, Droller MJ, Karakiewicz PI, Meryn S, Bochner BH. The effect of age and gender on bladder cancer: a critical review of the literature. BJU Int. 2009;105: 300-308. 